\title{
REFLEXIONES ANTE LA LEY DE LA INFANCIA DE LA COMUNIDAD VALENCIANA
}

\section{AGUSTÍN BUENO BUENO}

Profesor titular de Psicología Social de la Escuela Universitaria de Trabajo Social. Universidad de Alicante.

\section{$M^{\mathrm{a}}$ TERESA MIRA-PERCEVAL PASTOR}

Profesora titular de Servicios Sociales de la Escuela Universitaria de Trabajo Social. Universidad de Alicante.

\section{RESUMEN}

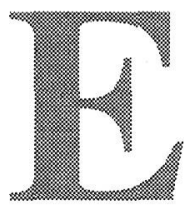

ste artículo presenta una lectura crítica de la Ley de la Infancia de la Comunidad Valenciana, recientemente aprobada y pendiente de su pleno desarrollo a través de los sucesivos reglamentos y decretos de aplicación. Tras una ligera contextualización histórico-legislativa, se analiza el sentido general de la Ley y los conceptos básicos que define de cara a la intervención social; por fin reflexionamos sobre lo que es punto central y más novedoso de ella: el Plan Integral de Atención a la Infancia.

\section{PALABRAS CLAVE}

Infancia, legislación, política social, servicios sociales, Comunidad Valenciana, intervención social.

\section{INTRODUCCIÓN}

El pasado día 16 de diciembre de 1994, apareció publicada en el Diario Oficial de la Generalitat Valenciana, la, Ley 7/94 de la Infancia ${ }^{1}$.

Ha sido un texto anhelado y cuestionado ampliamente por los profesionales de intervención social con menores, a través de los más de cinco borradores que ha experimentado durante el proceso de elaboración. Viene a llenar un vacío tremendo en este ámbito de la interven- 
ción, que hasta ahora se estaba cubriendo con decretos puntuales para unos programas $\mathrm{u}$ otros de actuación, pero sin que hubiera una perspectiva global en nuestra Comunidad.

La situación legal de los menores se había ido haciendo cada vez más ambigua. La antigua legislación, que databa de $1948^{2}$, había quedado inoperante. Desde la reforma del Código Civil (Ley 21/87) ${ }^{3}$ sobre enjuiciamiento civil en materia de adopción, no había ningún texto legal que articulase mínimamente la protección de la infancia a nivel de Estado; y desde la Ley 4/92 sobre competencias y pocedimientos de los Juzgados de Menores ${ }^{4}$ habían quedado modificados los procedimientos de actuación judicial en materia de reforma con los menores de dieciséis años, y además el cumplimiento de los acuerdos del Juez quedaba encomendado a las «entidades públicas» (comunidades autónomas y ayuntamientos) pero sin especificar el cómo.

Por otra parte, las Naciones Unidas en 1989 actualizaban la Declaración de los Derechos del Niño. España los ratificaba un año después ${ }^{5}$, asumiendo principios importantísimos que luego no siempre tenía posibilidades de cumplir.

Seguimos sin tener una ley de protección a la infancia de ámbito estatal, aunque a todos nos consta que se está trabajando en ella. Cuando tal texto resulte aprobado es fácil pensar que la Ley de la Comunidad Valenciana que ahora nos ocupa, tenga que ser revisada y actualizada.

Podemos, también, considerar que esta Ley de la Infancia ha venido a dar cumplimiento al artículo 31, apartados 24 y 27, del Estatuto de Autonomía de la Comunidad de Valencia, en cuanto a la promoción y defensa de los menores.

Para finalizar esta introducción ambientadora, caigamos en la cuenta de que se ha hecho un esfuerzo intencionado en excluir el término de «menor» del enunciado de la Ley, aunque nosotros por agilidad y costumbre volvamos de vez en cuando a ese término a lo largo de nuestra reflexión.

La intencionalidad del cambio de término es clara y acorde con el sentido general de la Ley. Pasar de una Ley del Menor a una Ley de la Infancia no es solo un cambio literario de estilo ni tampoco una acomodación social de género. El cambio significa la intención de los legisladores de desarrollar un instrumento educativo y de crecimiento, más que judicial y penal.

2 Decreto de 11 de junio de 1948: «Texto refundido sobre la legislación de Tribunales Tutelares de Menores»

$3 \quad$ B.O.E. N 275 de 17 de noviembre de 1987.

4 B.O.E. $N^{\circ} 140$ de 11 de junio de 1992.

s B.O.E. No 313 de 31 de diciembre de 1990. 
El término «menor» es de carácter jurídico y hace referencia a la edad penal y civil. Se indica con ese término a un sujeto atípico de la legislación, que necesita de un tratamiento especial: Juez de Menores, ahora también fiscalía, tribunales tutelares, centros de tratamiento o reforma, etc. «Infancia», en cambio, hace referencia a un sector social de la población que no es productivo todavía, que está en fase de desarrollo y crecimiento, facetas que hay que facilitar y defender. Esta intencionalidad desjuciadora de la Ley queda bien explicitada en el siguiente párrafo:

«... en la medida en que la inadaptación de la infancia y de la juventud es un proceso multicausal ${ }^{6}$ ya no es posible judicializar las medidas. En su lugar se impone la colaboración entre los órganos jurisdiccionales, la policía, las administraciones públicas y los agentes sociales, con una gran contribución de los medios de comunicación». (Preámbulo de la Ley, apartado 2 final)

\section{ALCANCEY OBJETO DE LA LEY}

Junto al panorama legislativo general, nacional y mundial que acabamos de contemplar, la Ley de la Infancia de la Comunidad Valenciana surge como respuesta a una necesidad tanto o más vital que jurídica; sobre todo si se piensa que lo jurídico y lo vital no son siempre realidades paralelas.

Pretender proteger, encauzar y desarrollar la infancia no es tarea que se pueda encomendar a un juez, ni a cualquier profesional, liberando de responsabilidad y competencias a los demás agentes de socialización. La sociedad entera, por lógica semántica y por concepción de la realidad social, ha de verse implicada en esa importante tarea. No se puede dejar fuera a los profesores de primaria y secundaria, ni a los profesionales sanitarios, ni a los trabajadores sociales, ni a los educadores, sean familia biológica o no. Pero, ¿quién decide lo que se ha de hacer?, ¿quién coordina a los sanitarios con los profesores, y a éstos con los educadores y con los trabajadores sociales, e incluso con los adjudicadores de viviendas protegidas? Porque, si no se les coordina, cada uno fácilmente irá a su aire y en la dirección que le parezca oportuno. El menor, amarrado al férreo potro de la administración, quedará descuartizado en aras de una incomprensible justiticia social.

6 El texto de la Ley lo que dice expresamente es que «la inadaptación (...) es un proceso multicasual». Entendemos que se trata de un error mecanográfico, no exento de ironía vital, y nos hemos permitido reordenar en la cita las letras de la importante palabra. 
En las I Jornadas sobre menores marginados del todavía País Valenciano $(1979)^{7}$ se pedía ya, como algo imprescindible para el trabajo de protección y reeducación de los niños y niñas de nuestra comunidad, «un organismo unitario que coordine toda la problemática en torno al menor» y que se estableciesen programas conjuntos de los distintos departamentos de la administración. Era claro que si cada uno programaba la actuación sobre la infancia desde su perspectiva y a su ritmo, se iría dando bandazos en temas tan importantes como salud, enseñanza, trabajo y tratamiento tras la sanción judicial de un menor.

Puede parecer absurdo pero, aún hoy, un Centro de Día con asistencia posible de los niños y adolescentes desde las 9 de la mañana hasta las 7 de la tarde incluyendo, además de la enseñanza de E.G.B. y la mediapensión, talleres de iniciación laboral, apoyo sanitario, psicológico y de trabajo social, no se puede costear con dinero público de una manera unitaria. Los distintos departamentos no tienen la flexibilidad suficiente para arbitrar el pago conjunto de un recurso complejo, con lo que eso significa de incremento de papeles y gestiones administrativas limitadoras de tiempo y personas para atender a los usuarios.

Afortunadamente pensamos que la nueva Ley de la Infancia puede servir para paliar este tipo de limitaciones y, más aún, para establecer una política coherente y coordinada de los distintos sectores. Este es el objeto central de la Ley tal como se desgrana en distintos párrafos del preámbulo de la misma:

«La presente ley tiene por objeto consolidar esta política integradora, preventiva, compensadora y de sensibilización cívica y social a través de los mecanismos de planificación, programación y evaluación conjunta entre todas las administraciones públicas y las instituciones sociales, que tendrá como eje el Plan Integral de Atención a la Infancia.

...La política social a favor de la infancia no necesita tanto una ampliación de recursos, cuanto una armonización, delimitación y coordinación de las políticas existentes.

Esta armonización de las políticas de infancia es la clave de bóveda de la presente Ley. Sólo de este modo es posible abordar la problemática del desamparo y de la inadaptación de las y los menores que tienen en las sociedades avanzadas un carácter transversal que se disemina a través de todos los sistemas del bienestar ...

La presente Ley intenta situar la política compensatoria que desarrollan los Servicios Sociales en el interior de los 
sistemas ordinarios así como promover y reforzar la coordinación entre los distintos departamentos ...» (Preámbulo de la Ley, extracto de los apartados 1 y 4 ).

\section{SÍNTESIS GENERAL DE LA LEY}

Podemos considerar que la Ley de la Infancia de la Comunidad Valenciana tiene dos partes fundamentales.

El preámbulo y el título preliminar pueden considerarse el cuerpo básico doctrinal. En esta primera parte aparecen los grandes principios que justifican la aparición de la Ley y que definen el alcance de la misma, tal como veíamos antes; también en ella se matizan conceptos claves: situación de riesgo, de desamparo e inadaptación, y se definen y precisan quiénes son los agentes de atención a la infancia (la Generalitat Valenciana, las Corporaciones Locales, las Unidades de Convivencia, las Instituciones de Integración Familiar, y la misma Infancia).

Como gozne entre esta primera parte más conceptual y la segunda más pragmática, el título primero presenta el Plan Integral de Atención a la Infancia (P.I.A.I.). Es lo más novedoso de la Ley, que luego comentaremos expresamente. En síntesis se trata de un proceso de planificación interdepartamental conjunta que comprende los ámbitos social, cultural, sanitario y de preparación al mundo laboral.

La segunda parte (títulos segundo y tercero) estructura los distintos tipos de programas que podrán dar cuerpo al PIAI, y que son: Información, accesibilidad, cooperación, convivencia y reinserción. Acaba con una breve referencia a la necesaria evaluación y control de los programas.

No hay especiales novedades en la gama de programas. Las especificaciones más sugerentes las veremos luego.

\section{ALGUNOS CONCEPTOS DELIMITADOS EN LA LEY}

\subsection{Concepto de niño/niña}

El artículo primero de la Ley establece el objeto de la misma y al hacerlo intenta clarificar el techo de edad de la protección a la infancia. Textualmente dice: «Se entiende por niño y niña, a los efectos de esta Ley, todo menor de edad».

La mayoría de edad, así sin adjetivos, en España se alcanza a los 18 años. Esto significa que todos los programas que en esta ley se desarrollan son aplicables hasta los 18 años, incluidos los programas de reinserción social que comprenden las medidas judiciales que puede tomar un Juez de menores. 
¿Significa esto que la edad penal ha pasado de los 16 a los 18 años? No es éste el ámbito de competencias para hacerlo, sino la reforma del Código Penal actualmente pendiente de su elaboración en las Cortes de Madrid. Todo parece intuir que efectivamente el nuevo Código Penal contemplará los 18 años como límite de edad penal, paralela a la mayoría de edad civil. Entretanto se apruebe esa reforma, un/a adolescente de la Comunidad Valenciana entre los 16 y los 18 años podrá estar bajo la decisión de un Juez de Menores o de otro ordinario según la interpretación que se haga de su situación.

Una vez se confirme el cambio de límite en la edad penal, los 16 años quedarán exclusivamente como momento potestativo de acceso al mundo laboral. La LOGSE, por su parte, establece como límite superior de la enseñanza obligatoria y gratuita los mismos 16 años, pero con la posibilidad de ampliarse en dos años más si el alumno o alumna no ha alcanzado todavía los objetivos establecidos.

Hemos de alegramos de que, frente a las voces todavía recientes de rebajar la edad penal a los catorce años, prevalezca la opción más sensata de los dieciocho.

\subsection{Situación de riesgo}

El concepto de riesgo social nos ha llegado derivado de las ciencias de la salud, en su acepción de elementos determinantes del peligro de padecer un determinado trastorno o enfermedad. Es fruto de la investigación multivariada que nos ha ido llevando a la consideración de que pocas enfermedades (salvo las de origen infeccioso, y aun éstas admiten matices) tienen una única causa.

Si la afirmación de que la enfermedad física es fruto de la confluencia de diversos factores o circunstancias de índole personal y ambiental ha ido adquiriendo evidencia en las últimas décadas, la misma afirmación resulta más rotunda en el terreno de la salud/enfermedad social.

La Ley de la Infancia indica como situación de riesgo «aquélla en la que por sus circunstancias personales o por influencias de su entorno o extrañas, exijan la adopción de medidas de prevención y rehabilitación para evitar situaciones de desamparo o de inadaptación social» (Artículo segundo).

Sin duda, se pretende con la introducción de este concepto al comienzo de la Ley despersonalizar, y desculpabilizar en parte, las conductas delictivas de los menores, y generar al mismo tiempo respuestas eficaces.

La intención es laudatoria y apunta directamente a la prevención, igual que en el supuesto de la salud física. Conocer los factores de riesgo de las fiebres tifoideas o del infarto de miocardio, sirve para tomar las medidas oportunas que hagan más difícil o tardía su apari- 
ción. En el campo psicológico y social la lógica es la misma, pero los factores de riesgo son tan numerosos, tan complejos y, con frecuencia, tan alejados del control personal o de los mismos servicios sociales municipales y autonómicos, que puede ser más adecuado compararlos con los factores de riesgo de la contaminación atmosférica.

Inseparable del concepto de riesgo social es el de prevención. Conocer los riesgos tiene sentido para adelantarse a ellos y evitarlos, previniendo así el mal último o enfermedad.

En la intervención social falla, o falta, un concepto claro de enfermedad social, cuya delimitación permitiría establecer que el proceso previo hasta llegar a ella significa actuaciones de prevención. Mientras que el tifus o el infarto se tienen o no, y mientras que no se tienen se puede intentar la prevención; el desamparo y la inadaptación, que son las enfermedades sociales que la ley trata de prevenir (Artículo segundo), no son situaciones de estado sino de proceso.

Efectivamente hay situaciones de grado máximo: estar en la cárcel, no tener domicilio, etc.; pero existen infinidad de situaciones de grado intermedio: hacer novillos, ser expulsado del colegio, tener al padre en paro y alcohólico, etc. Actuar en estos niveles intermedios es a la vez prevención y tratamiento, porque se trata de factores de riesgo encadenados. Cuando en un individuo, familia o colectivo se dan una serie de factores de riesgo ya hay un cierto grado de enfermedad social, que si no se trata dará origen a un paulatino agravamiento, y cuyo tratamiento será prevención de los procesos malignos superiores aunque no evitación radical de la enfermedad.

Buena parte de los factores de riesgo social hay que buscarlos en los aspectos estructurales de la sociedad, y una prueba de ello, que ahora no es momento de desarrollar, es que los factores de riesgo social no son en todas las sociedades los mismos.

\subsection{Situación de desamparo}

Para definir la situación de desamparo la Ley de la Infancia nos remite al Código Civil ${ }^{8}$, que hace referencia al incumplimiento de los deberes de protección de los menores. El problema surge al concretar el citado artículo del Código Civil los deberes de protección en «la necesaria asistencia ética, moral y material».

Desde un análisis psicosocial de la protección/desprotección de los niños y adolescentes, semejante formulación no es clara. Será válida para situaciones extremas, pero inadecuada totalmente para detectar 
factores de riesgo que exijan (como decía la Ley antes) «medidas de prevención».

Pongamos una comparación sencilla. Una chaval querido y atendido por su madre, mujer soltera que trabaja en la prostitución de manera consciente y voluntaria, tiene más probabilidades de ser declarado en situación de desamparo que el hijo de una madre soltera, casada con posterioridad, y criado en una familia donde no se le quiere, se le humilla y se le considera una vergüenza. Las comparaciones siempre son odiosas, y en este caso también; pero ayudan a la reflexión.

De cara a la intervención social hubiera sido más claro hablar en términos de gama de necesidades carentes y cubiertas, y arbitrar después los límites aceptables o las formas de diagnóstico.

\subsection{Situación de inadaptación}

La inadaptación, o la conducta inadaptada, siempre han sido conceptos y fenómenos relativos; en función siempre de un contexto normalizado de referencia. Es en este contexto de referencia donde cabe nuestra reflexión.

Comer objetos de plástico o dormir de pie o sobre púas, sin duda hay que considerarlos como situaciones o conductas inadaptadas; pero inadaptadas a la naturaleza humana: no es bueno al ser humano hacer tales cosas.

Acudir con una máquina de escribir a una playa de moda en verano, podemos considerarlo también una conducta inadaptada, pero de índole muy distinta a las primeras. En este caso estaremos ante una conducta inadaptada por lo inusual, por lo incómoda o poco adaptativa a la funcionalidad tanto de la playa como de la máquina de escribir. Pero ahí se acaba su inadaptación. Puede ser perfectamente adaptada a otras claves de comprensión. Por ejemplo: una apuesta, o un reportaje publicitario de máquinas de escribir o de playas.

El sentido que da la Ley al término inadaptación es el de referencia jurídica y penal:

«Se considera situación de inadaptación aquélla que es declarada mediante resolución judicial, en los términos previstos por la Ley Orgánica de Reforma de la Ley Reguladora de la Competencia y el Procedimiento de los Juzgados de menores, y que exige la adopción de medidas de resocialización e inserción». (Artículo segundo)

Lógicamente, las conductas establecidas en nuestro Código Penal como constitutivas de delito son conductas inadaptadas a nuestra sociedad. Es a ésas y sólo a esas conductas a las que se refiere esta Ley, que es una ley básicamente de Servicios Sociales, en cuanto necesitadas de reinserción y rehabilitación. 
Cabría entrar a preguntarse porqué la mendicidad es una conducta inadaptada; o si hay inadaptación en el hecho de que los menores de dieciocho años tomen bebidas alcohólicas o fumen. Igualmente es importante constatar que en una ley de Servicios Sociales no aparezcan como conductas inadaptadas, y por lo tanto necesitadas de medidas de cambio, aquéllas que impiden o dificultan el adecuado y necesario desarrollo físico, psíquico y sociocultural de los menores.

\section{EL PLAN INTEGRAL DE ATENCIÓN A LA INFANCIA}

Ya hemos comentado antes que el P.I.A.I., como instrumento coordinador de las políticas sobre la infancia, es el punto central de la Ley, en cuanto elemento cualitativo nuevo y como eje estructurador práctico de los programas que siguen en ella y de cualquier otro programa de cualquier otra Consellería.

El Plan Integral de Atención a la Infancia hay que concebirlo como la parte específica relativa a la infancia (0-18 años) de la planificación general de la política del Gobierno Valenciano. Como las decisiones del gobierno que afectan a la infancia pueden proceder de departamentos muy diversos, en esta Ley ${ }^{9}$ se arbitra el procedimiento básico para elaborar y aprobar las iniciativas de todos ellos.

El P.I.A.I. comprenderá los ámbitos social, cultural, educativo, sanitario y de preparación al mundo laboral. Cada una de las Consellerías competentes en estos ámbitos elaborará su propuesta de planificación, fundamentada con estudios y consultas previas sobre necesidades, y acompañada de los correspondientes presupuestos y previsión de resultados.

Reunidos, parece ser, representantes de las diferentes Consellerías afectadas «en colaboración con las entidades ciudadanas apropiadas» harán la planificación conjunta que será presentada al Gobierno Valenciano por el Conseller de Trabajo y Asuntos Sociales. El P.I.A.I. allí aprobado tendrá una vigencia de tres ejercicios presupuestarios, prorrogables pero también revisables antes de finalizar el trienio.

Cabe añadir que el P.I.A.I. será único para todo el territorio de la Comunidad Valenciana. No obstante, el desarrollo del mismo podrá ser adaptado de manera específica en «demarcaciones territoriales» de características socioeconómicas, demográficas, familiares y de recursos homogéneos, a juicio de la Generalitat Valenciana.

Hasta aquí una sucinta presentación de lo que se esboza como Plan Integral de Atención a la Infancia. Alabamos el esfuerzo que, si se 
juzga por el tiempo que se ha tardado en conseguir, ha sido importante. Desde nuestra óptica de la puesta en práctica, para la intervención, es inevitable una perspectiva de futuro, aunque sea para prevenir el desarrollo de la Ley.

El primer interrogante que nos surge es sobre quién elaborará el P.I.A.I.. Está claro que «las Consellerías afectadas en colaboración con las entidades ciudadanas apropiadas (organizaciones de voluntariado, representación familias acogida, instituciones de acogida, asociaciones de vecinos)». La cuestión está en lo de apropiadas. ¿Para quién? ¿Para qué? Se puede ser apropiado para gastar poco, para hacerlo de manera sumisa, para hacerlo como a mí me gusta, para hacerlo de manera eficiente aunque cara, etc. Es importante que el término entidades ciudadanas apropiadas no se determine de manera arbitraria.

En esta misma faceta del sujeto planificador echamos en falta la presencia de las entidades locales y los profesionales de pie de obra. Es cierto que en el Artículo once se les hace aparecer al decir: «Cada administración, en el ámbito de sus competencias, elaborará instrumentos para la detección de las necesidades a través de sus sistemas de atención primaria». El punto de partida de cualquier planificación seria ha de ser efectivamente un estudio de necesidades. Encomendar buena parte del estudio a los correspondientes profesionales de atención primaria es una medida eficaz (los maestros saben lo que ocurre en la aulas; trabajadores sociales, educadores, psicólogos, etc. saben lo que ocurre en los centros sociales; médicos, trabajadores sociales, diplomados en enfermería, conocen los centros de salud; etc.). Tomar de ellos esa información, irla pasando hacia arriba, retocándola, reelaborándola y sintetizándola en un P.I.A.I. por personas de despacho exclusivamente, y luego devolvérsela desconocida, en forma de norma de actuación a los profesionales de atención primaria para que la ejecuten, es una cosa muy fea. Hay que pensar bien la fórmula para que no se pierda el hilo conductor entre: detección de necesidades -elaboración del plan- ejecución de las medidas.

Pasando de lo que sería la fase operativa inicial del P.I.A.I. (detección) a la final de ejecución, hemos de constatar que la ejecución de la política de la Generalitat Valenciana no puede quedar al arbitrio de que un municipio quiera o no quiera implantar tal programa, o que la Generalitat quiera pero no facilite los medios o los facilite de manera inadmisible.

Lo mismo puede decirse sobre la territorialidad de los programas por demarcaciones homologadas por la Generalitat Valenciana. Está bien este criterio de flexibilidad, pero en la homologación en función de criterios socioeconómicos, demográficos que veíamos antes (Art. ${ }^{\circ}$ 12) no debería haber dudas ni discusiones. Hay medios asequibles para establecer criterios de homologación suficientemente objetivos. Sin 
embargo, es fácil que en este punto, como en el anterior, de diagnóstico-ejecución, entren en contradicción los criterios técnicos y los criterios políticos. No vamos a entrar ahora en ese tema árduo y prolijo del ¿qué hacer?, ¿cómo hacer?, ¿cuándo hacer? de la intervención social vista desde el técnico y desde el político.

Si hemos dicho una palabra de las fases inicial y final del P.I.A.I., nos queda algo muy importante en la fase intermedia de aprobación: la Consellería de Hacienda. No nos hagamos ilusiones, ni juguemos con las ilusiones ajenas (de usuarios y profesionales). Si no va a haber el dinero necesario y en el momento en que hace falta, es preferible que se apruebe un P.I.A.I. más modesto e incluso vergonzoso para quien lo aprueba. Pero que lo bien planificado y aprobado, no tenga ningún problema económico de ejecución, ni en cantidad ni en plazos. Lo contrario es contraproducente para todos: los políticos pierden credibilidad, los técnicos se queman profesionalmente, los usuarios se sienten burlados.

\section{PUNTO FINAL}

El resto de la Ley comprende los cinco bloques de programas preceptivos que ha de incluir el P.I.A.I.. No hay especiales novedades en este desglose de programas ni en la atribución de competencias: los de carácter general corresponden a los ayuntamientos y los especializados a la Generalitat.

No obstante llama doblemente la atención entre los programas de convivencia (facilitadores de convivencia), la presencia de la terapia familiar como servicio de atención especializada. El párrafo concreto que lo indica está en el artículo veinticinco: «La terapia familiar dirigida a aplicar a una unidad de convivencia prestaciones técnicas que permitan abordar los conflictos relacionales y la desestructuración familiar».

Los párrafos siguientes citan los otros dos servicios de atención especializada a la convivencia: el acogimiento de carácter especializado, sea familiar o residencial, y la propuesta de adopción. Lo curioso es que, a continuación, el artículo veintiséis desarrolla el acogimiento familiar de carácter especializado, el veintisiete el acogimiento en residencia, y el veintiocho la adopción; sin embargo, el recurso de terapia familiar, sin duda tan necesario e importante como los otros, no queda ampliado en ningún otro sitio.

Los últimos artículos de la Ley están dedicados al seguimiento y evaluación de los programas presentados. Se habla, en términos generales, de su necesidad y competencias. Es muy poco específico lo que se dice, pero lo suficiente para que no se deba desarrollar un programa 
de Servicios Sociales sin establecer previamente criterios de evaluación. La Ley podía haber sido más taxativa a este respecto. Es un terreno difícil, donde nuevamente lo técnico, lo político, lo corporativo, pueden entrar en colisión, pero precisamente por eso es más urgente que quede claro.

Hemos sido críticos con la Ley de la Infancia de la Comunidad Valenciana, porque la consideramos importante y porque deseamos que su desarrollo sea eficaz. La Ley es un paso importante en la política social respecto de los niños y jóvenes, pero es ambigüa en algunos puntos e incompleta en otros. Merece la pena que los decretos que la desarrollen la vayan aclarando y mejorando. 